\title{
Preparation and Evaluation of Emamectin Benzoate Solid Microemulsion
}

\author{
Lei Feng, Bo Cui, Dongsheng Yang, Chunxin Wang, Zhanghua Zeng, Yan Wang, \\ Changjiao Sun, Xiang Zhao, and Haixin Cui
}

Institute of Environment and Sustainable Development in Agriculture, Chinese Academy of Agricultural Sciences, Beijing 100081, China

Correspondence should be addressed to Haixin Cui; cuihaixin@caas.cn

Received 3 February 2016; Accepted 17 April 2016

Academic Editor: William Yu

Copyright (C) 2016 Lei Feng et al. This is an open access article distributed under the Creative Commons Attribution License, which permits unrestricted use, distribution, and reproduction in any medium, provided the original work is properly cited.

The solid microemulsions of emamectin benzoate with the same content of surfactants were prepared by a self-emulsifying method. Emulsifier $600^{\#}$ and emulsifier $700^{\#}(3 / 2, w / w)$ screened from eleven kinds of commonly used surfactants displayed great emulsifying properties. The redispersed solution of the solid microemulsion presented aqueous microemulsion characteristic. The mean particle size and polydispersity index were $10.34 \pm 0.10 \mathrm{~nm}$ and $0.283 \pm 0.013$, respectively. The solid microemulsion showed excellent storage stability and the bioassay compared with water dispersible granules against diamondback moths provided a proof of its improved biological activities. This formulation could significantly reduce surfactants and is perspective in plant protection for improving bioavailability and environmental friendliness.

\section{Introduction}

Pesticides are commonly used in agriculture to improve crop yield and quality by controlling plant diseases [1]. Most pesticides must be formulated using suitable formulations to keep bioactivity and enhance efficacy, safety, and convenience of the active ingredients while spraying. Conventional pesticide formulations mainly include emulsifiable concentrate (EC), wettable powder (WP), and suspension concentrate (SC) [2]. In the EC formulation, large amounts of organic solvents such as toluene and xylene are used as main components which are toxic, inflammable, and explosive [3]. In general, the emulsifiers in the conventional formulation compositions consist of ionic surfactants (calcium dodecylbenzenesulfonate, polycarboxylates, and so forth) and nonionic surfactants (dibenzyl phenol polyoxyethylene ether, nonylphenol ether, and so forth). The amount of surfactants is mainly equal to or higher than $8 \%$ of the total weight in these formulations [4-7]. In addition, wetting agents, such as alcohol ethoxylate, sodium dodecyl sulfate, and alkylphenol ethoxylates, are always needed to keep the stability and dispersibility of WPs and SCs besides carriers and other additives $[8,9]$.

Most pesticide compounds are poorly soluble in aqueous media, which limits the development of their efficient and green formulations $[1,10]$. According to the OstwaldFreundlich equation (1), with all other factors kept constant, the solubility increases with particle size decreasing [11]. One has

$$
\frac{S(d)}{S_{0}}=\exp \frac{\gamma V_{m}}{R T d},
$$

where $S(d)$ is the solubility $(\mathrm{mol} / \mathrm{kg})$ of the pesticide with particle diameter $d(\mathrm{~m})$ at temperature $T(\mathrm{~K}) ; S_{0}$ is the solubility of the bulk pesticide; $V_{m}$ is molar volume $\left(\mathrm{m}^{3} / \mathrm{mol}\right)$; $\gamma$ is surface free energy $\left(\mathrm{J} / \mathrm{m}^{2}\right) ; R$ is the gas constant. It means that reducing particle size of the pesticide is an effective method to enhance its dissolution rate $[12,13]$. However, significant change occurs only with a particle size in the nanorange [14]. In this case, nanotechnology could be a new strategy to produce nanopesticides for improving the solubility of poorly soluble pesticides $[14,15]$.

Emamectin benzoate, a macrocyclic lactone insecticide (Figure 1), is a semisynthetic derivative of the avermectins [16-18]. It shows a broad spectrum, high efficiency, and low toxicity, which is further improved with thermal stability than avermectin [19]. Because its water solubility is extremely low $\left(24 \mathrm{mg} / \mathrm{L}^{-1}\right)$, the dominant formulation of emamectin 


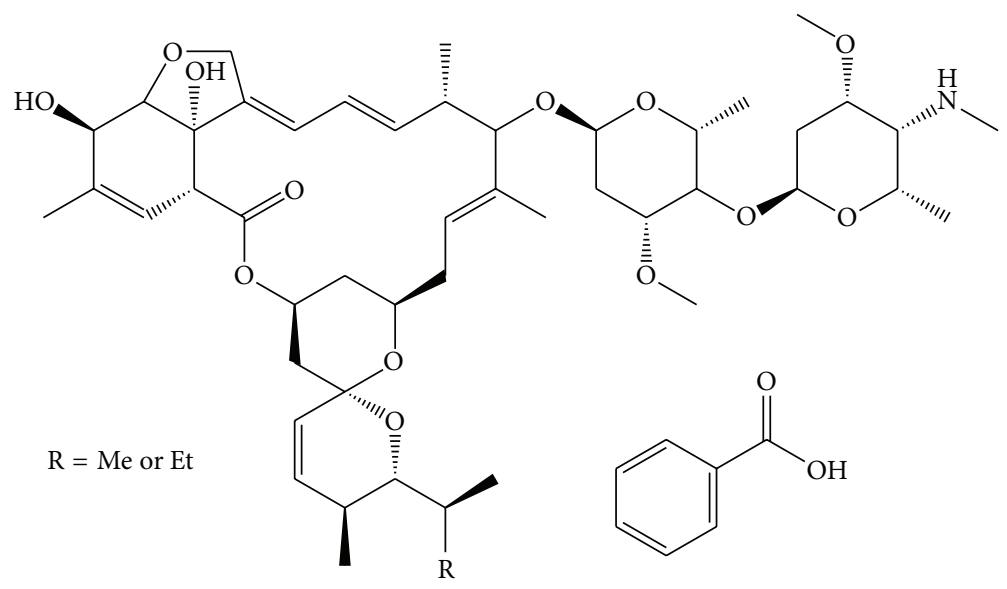

FIGURE 1: Chemical structure of emamectin benzoate.

benzoate is still EC at present with low pesticide content and a large amount of organic solvent [20]. Though microemulsion of emamectin benzoate has emerged to reduce organic solvent, few studies were reported, especially the solidified microemulsion.

In this study, we prepared emamectin benzoate solid microemulsions (SMEs) using a self-emulsifying method. The solid nanoformulation presented excellent dispersibility, stability, and efficiency. In addition, the surfactant content in the composition was equal to that of pesticide which was much lower than most other self-emulsified systems. The solid microemulsion provides a novel strategy to develop a solid nanoformulation with enhanced environmental friendliness and safety and may become a desired alternative for conventional formulations.

\section{Experimental Methods}

2.1. Materials. Emamectin benzoate (95\%) was purchased from Hebei Veyong Bio-Chemical Co., Ltd. Styryl phenol polyoxyethylene ether (emulsifier $600^{\#}$ ), alkylphenol formaldehyde resin polyoxyethylene ether (emulsifier $700^{\#}$ ), phenylethyl phenol polyoxyethylene polyoxypropylene ether (emulsifier $1601^{\#}$ ), Silwet 408, and polyoxyethylene (40) castor oil ether (EL-40) were purchased from Cangzhou Hongyuan Agrochemical Co., Ltd. Polyoxyethylene sorbitan monooleate (Tween 80), polyethylene glycol mono4-nonylphenyl ether (PGME), sodium dodecylbenzenesulfonate (SDBS), and calcium dodecylbenzenesulfonate (CDBS) were purchased from J\&K Chemical. Maleic rosinpolyoxypropylene-polyoxyethylene ether sulfonate (MRES) and polycarboxylate were provided by Jiangsu Sinvochem S\&D, Ltd. Two emamectin benzoate water dispersible granules were purchased from Shaanxi Sunger Road Bio-Science Co., Ltd. (WDG-A), and Qingdao Star Cropscience Co., Ltd. (WDG-B), respectively. HPLC grade methanol, acetonitrile, and ammonium acetate were purchased from Fisher. Milli-Q water $(18.2 \mathrm{M} \Omega \cdot \mathrm{cm}$, TOC $\leqslant 4 \mathrm{ppb})$ was used in all analytical experiments.
2.2. Preparation of Emamectin Benzoate SMEs. Considering the formulation composition changed with different pesticide contents, the preparation process of $2.8 \%$ emamectin benzoate SME was taken as an example to be described in detail as follows. $2.95 \mathrm{~g}$ emamectin benzoate was dissolved in ethyl acetate and mixed with $2.8 \mathrm{~g}$ surfactants. Then $94.25 \mathrm{~g}$ sodium benzoate as carrier was added to adsorb the solution. After stirring evenly, the mixture was dried using an oven (DHG9070A, Shanghai Yiheng Scientific Instrument Co., Ltd.) at $40^{\circ} \mathrm{C}$ for $1 \mathrm{~h}$ to obtain emamectin benzoate SMEs.

2.3. Particle Size of Nanoparticles. The mean particle size and polydispersity index (PDI) of the redispersed aqueous microemulsion were measured by dynamic light scattering (DLS) with a Zetasizer Nano ZS90 (Malvern Instruments, $\mathrm{UK})$ at $25^{\circ} \mathrm{C}$. The measurement was carried out in triplicate for each sample.

2.4. Morphology Characterization of Nanoparticles. The morphology of emamectin benzoate nanoparticles was characterized by scanning electron microscopy (SEM) (JSM$7401 F$, JEOL, Japan) with an accelerating voltage of $3 \mathrm{kV}$. The samples were dropped on freshly cleaned silicon slice, dried naturally, and coated with a thin layer of platinum for $30 \mathrm{~s}$ with ETD-800 sputter coater (Beijing Elaborate Technology Development Ltd., China).

2.5. Crystalline State Analysis of Nanoparticles. The crystalline state of emamectin benzoate nanoparticles was characterized by an X-ray diffractometer (Bruker AXS Inc., D8 Advance, Germany) with $\mathrm{Cu} \mathrm{K} \alpha$ radiation generated at $40 \mathrm{kV}$ voltage and $40 \mathrm{~mA}$ current. Samples were analyzed in a $2 \theta$ range of $5-50^{\circ}$, with a step size of $0.02^{\circ}$ and a time step of $0.1 \mathrm{~s}$.

2.6. HPLC Analysis. The emamectin benzoate content was analyzed by high performance liquid chromatography (HPLC) (WAT035876, Waters Co., Milford, USA) using a C18 column (5 $\mu \mathrm{m}, 4.6 \mathrm{~mm} * 250 \mathrm{~mm}$, Shiseido, Japan) and $245 \mathrm{~nm} \mathrm{UV}$ 
TABLE 1: The influence of single surfactant on the mean particle size and PDI of SMEs.

\begin{tabular}{lcc}
\hline Surfactant & Mean particle size $(\mathrm{nm})$ & PDI \\
\hline Emulsifier $600^{\#}$ & $21.11 \pm 0.68^{\mathrm{h}}$ & $0.716 \pm 0.032^{\mathrm{bc}}$ \\
Emulsifier $700^{\#}$ & $55.47 \pm 3.93^{\mathrm{gh}}$ & $0.406 \pm 0.096^{\mathrm{d}}$ \\
Emulsifier $1601^{\#}$ & $33.94 \pm 9.71^{\mathrm{h}}$ & $0.535 \pm 0.165^{\mathrm{cd}}$ \\
Silwet 408 & $249.30 \pm 5.75^{\mathrm{d}}$ & $0.456 \pm 0.015^{\mathrm{d}}$ \\
Tween 80 & $418.87 \pm 9.88^{\mathrm{c}}$ & $0.745 \pm 0.051^{\mathrm{b}}$ \\
EL-40 & $638.00 \pm 61.28^{\mathrm{b}}$ & $0.171 \pm 0.075^{\mathrm{e}}$ \\
PGME & $122.43 \pm 6.33^{\mathrm{f}}$ & $0.950 \pm 0.039^{\mathrm{a}}$ \\
MRES & $36.02 \pm 4.27^{\mathrm{h}}$ & $0.969 \pm 0.044^{\mathrm{a}}$ \\
Polycarboxylate & $89.45 \pm 1.32^{\mathrm{fg}}$ & $0.742 \pm 0.046^{\mathrm{b}}$ \\
SDBS & $440.07 \pm 5.54^{\mathrm{c}}$ & $0.535 \pm 0.061^{\mathrm{cd}}$ \\
CDBS & $187.67 \pm 3.71^{\mathrm{e}}$ & $0.497 \pm 0.111^{\mathrm{d}}$ \\
\hline
\end{tabular}

Different letters at each data value indicate significant differences according to Duncan's multiple range test at $P<0.05$.

detector. The mobile phase was a mixture of methanol, acetonitrile, and $0.02 \%$ aqueous ammonium acetate $(42: 42: 16$, $\mathrm{v} / \mathrm{v})$ and the flow rate was $1.0 \mathrm{~mL} / \mathrm{min}$.

2.7. Statistical Analysis. In the surfactant screening process, the particle sizes were expressed as the mean \pm standard deviation (SD) and the statistical significance of the difference was examined using one-way analysis of variance (ANOVA) and Duncan's multiple range test. Results with a probability $(P)$ of less than 0.05 were considered to be statistically significant.

\section{Results and Discussion}

\subsection{The Influence of Surfactant on the Particle Size and Dispersibility of SMEs}

3.1.1. The Influence of Single Surfactant. Table 1 shows the mean particle sizes and PDIs of SMEs which were stabilized with eleven single surfactants, including eight nonionic type surfactants and four anionic type surfactants. The mean sizes of particles prepared with emulsifier $600^{\#}$, emulsifier $700^{\#}$, emulsifier $1601^{\#}$, MRES, and polycarboxylate were less than $100 \mathrm{~nm}$. The PDI value less than 0.3 reflects a good uniformity of particle diameter and can be used to depict the stability of the system [21, 22]. However, all the PDIs of the above SMEs were more than 0.4, indicating a wide size distribution. Among the eleven surfactants, EL-40 had significant effects in decreasing PDI. In order to obtain a stable solid nanoformulation, emulsifier $600^{\#}$, emulsifier $700^{\#}$, emulsifier $1601^{\#}$, MRES, polycarboxylate, and EL-40 were chosen for further investigation.

3.1.2. The Influence of Complex Surfactants. Five complex surfactants were used to produce emamectin benzoate SMEs. Considering that emulsifier $600^{\#}$ was the most efficient to reduce the particle size, it was fixed $(60 \%, w / w)$ to mix with the other surfactants $(40 \%, w / w)$. As shown in
TABLE 2: The influence of complex surfactants on the mean particle size and PDI of SMEs.

\begin{tabular}{lcc}
\hline Surfactant & Mean particle size $(\mathrm{nm})$ & PDI \\
\hline $600^{\#}+1601^{\#}$ & $69.74 \pm 20.01^{\mathrm{ab}}$ & $0.638 \pm 0.166^{\mathrm{a}}$ \\
$600^{\#}+$ MRES & $51.38 \pm 10.32^{\mathrm{bc}}$ & $0.456 \pm 0.042^{\mathrm{bc}}$ \\
$600^{\#}+$ polycarboxylate & $97.54 \pm 26.30^{\mathrm{a}}$ & $0.429 \pm 0.072^{\mathrm{bc}}$ \\
$600^{\#}+700^{\#}$ & $10.34 \pm 0.10^{\mathrm{d}}$ & $0.283 \pm 0.013^{\mathrm{c}}$ \\
$600^{\#}+$ EL-40 & $80.72 \pm 0.52^{\mathrm{ab}}$ & $0.558 \pm 0.001^{\mathrm{ab}}$ \\
\hline
\end{tabular}

Different letters at each data value indicate significant differences according to Duncan's multiple range test at $P<0.05$.

TABLE 3: The influence of different ratios of emulsifier $600^{\#}$ to emulsifier $700^{\#}$ on the mean particle size and PDI of SMEs.

\begin{tabular}{lcc}
\hline $\begin{array}{l}\text { Ratio of emulsifier } \\
600^{\#} \text { to emulsifier }\end{array}$ & Mean particle size $(\mathrm{nm})$ & PDI \\
$700^{\#}$ & & \\
\hline $3 / 2$ & $10.34 \pm 0.10^{\mathrm{b}}$ & $0.283 \pm 0.013^{\mathrm{b}}$ \\
$2 / 3$ & $19.83 \pm 1.14^{\mathrm{a}}$ & $0.739 \pm 0.046^{\mathrm{a}}$ \\
$1 / 1$ & $19.68 \pm 0.61^{\mathrm{a}}$ & $0.760 \pm 0.031^{\mathrm{a}}$ \\
\hline
\end{tabular}

Different letters at each data value indicate significant differences according to Duncan's multiple range test at $P<0.05$.

Table 2, the combination of emulsifier $600^{\#}$ and emulsifier $700^{\#}(3 / 2, w / w)$ reduced the mean particle size and PDI to $10.34 \pm 0.10 \mathrm{~nm}$ and $0.283 \pm 0.013$, respectively, which were smaller than other combinations. Emamectin benzoate is positively charged after being dispersed in water; anionic surfactants may induce particle aggregation via electrostatic interaction, so the optimized surfactant was of nonionic type. In addition, the polymeric surfactants adsorbing on the surface of emamectin benzoate can also afford steric barrier between particles. Therefore, the combination of emulsifier $600^{\#}$ and emulsifier $700^{\#}$ was chosen to prepare the emamectin benzoate SMEs.

Table 3 shows the effect of different ratios of emulsifier $600^{\#}$ to emulsifier $700^{\#}$ on the particle size and distribution of SMEs. When the ratio was $3 / 2$, the mean particle size and PDI were the smallest. Though both emulsifier $600^{\#}$ and emulsifier $700^{\#}$ belong to polyoxyethylene ethers surfactants, the differences in structure make emulsifier $600^{\#}$ more effective in decreasing particle size and improving uniformity $(P<0.05)$. Then the $3 / 2$ ratio with higher content of emulsifier $600^{\#}$ was chosen.

3.1.3. The Influence of Surfactant Content. The surfactant content plays an important role in stabilizing nanoparticles, especially in self-emulsified microemulsions [23]. As shown in Figure 2, the mean particle size of SMEs decreased with increasing surfactant concentration from 0.5 -fold to 4 -fold that of the active ingredient. When the surfactant content was the same as pesticide, the particle size and PDI decreased sharply to $30 \mathrm{~nm}$ and 0.221 , respectively. However, there was no significant change in particle size and dispersibility when increasing the ratio of surfactant to pesticide from 4 


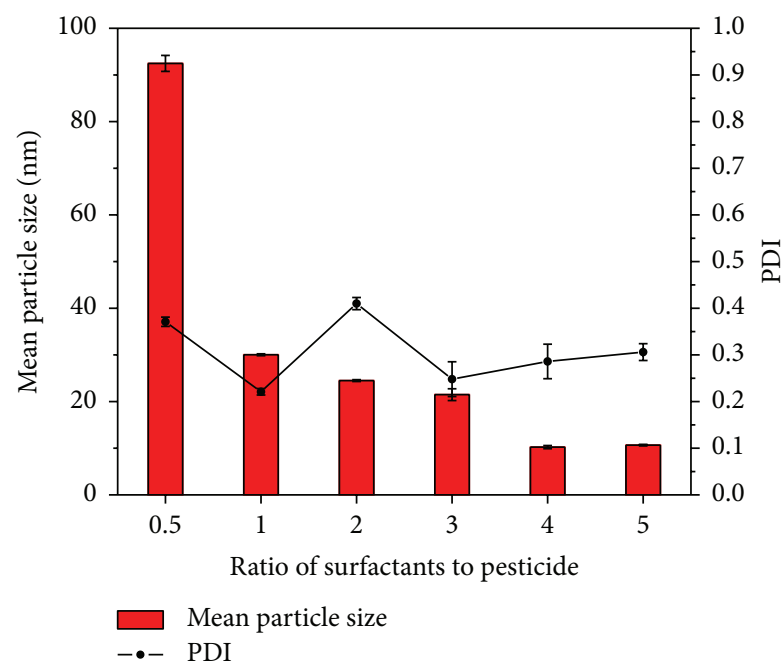

FIGURE 2: The influence of surfactant content on the mean particle size and PDI of SMEs.

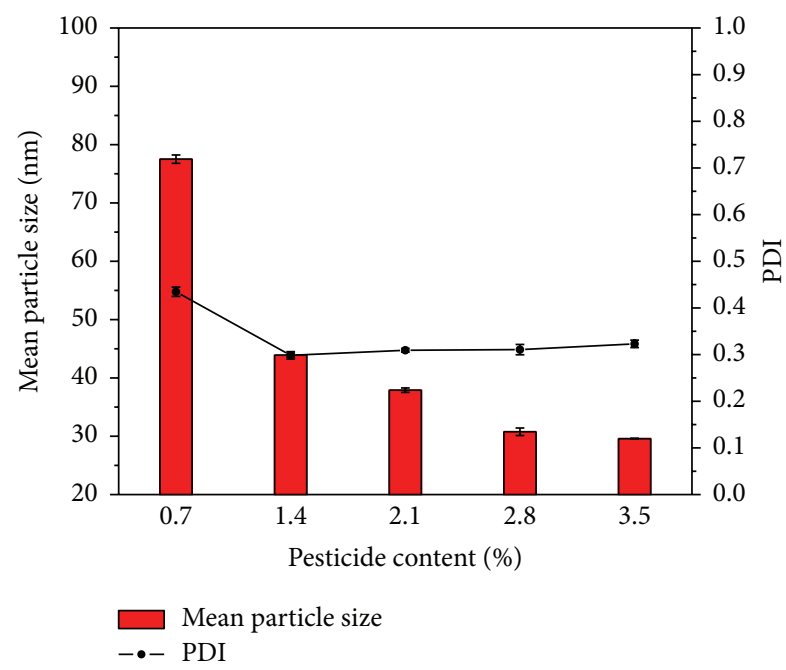

FIgURE 3: The influence of pesticide content on the mean particle size and PDI of SMEs.

to 5 . Above all, the 1:1 ratio was used for the preparation of emamectin benzoate SMEs. In order to achieve selfemulsifying property, the surfactant contents in aqueous microemulsions are usually larger than twice that of the active ingredient even in the presence of cosolvents [20, $24,25]$. Furthermore, they are normally more than 5 times in solid self-emulsifying formulations [26-28]. In contrast, the composition of emamectin benzoate SME significantly decreased the surfactant amount and revealed great advantages in environmental friendliness and production cost.

3.2. The Influence of Pesticide Content on the Particle Size and Dispersibility of SMEs. The emamectin benzoate SMEs with different pesticide concentrations have been prepared. Figure 3 shows that the mean particle size decreased from $77.51 \mathrm{~nm}$ to $29.58 \mathrm{~nm}$ as emamectin benzoate concentration increased from $0.7 \%(\mathrm{w} / \mathrm{w})$ to $3.5 \%(\mathrm{w} / \mathrm{w})$. During the preparation of SMEs, ethyl acetate dissolving pesticide increased with increasing emamectin benzoate content. When the amount of solution was beyond the absorption capability of sodium benzoate carrier, the mixture could not form solid state and the particle size became larger after drying. Therefore, the $2.8 \%$ emamectin benzoate SME was chosen for the detailed characterization.

3.3. Morphology of Nanoparticles. In the SEM imaging, sodium benzoate as carrier formed large crystals during the drying process and made it difficult to observe the small nanoparticles, so the aqueous dispersion without carrier was prepared and imaged. The pesticide nanoparticles presented irregular shape as observed in Figure 4(a). The particle size based on SEM imaging was from $20 \mathrm{~nm}$ to $50 \mathrm{~nm}$, which was well in agreement with the result measured by DLS (Figure 4(b)).

3.4. Crystalline State of Nanoparticles. The crystalline state of nanoparticles has significant impact on the solubility, stability, and bioavailability of nanoformulations [29]. Figure 5 shows the X-ray powder diffractogram profiles of emamectin benzoate, emulsifier $600^{\#}$, emulsifier $700^{\#}$, sodium benzoate, and emamectin benzoate SME. As shown in the patterns, emamectin benzoate, emulsifier $600^{\#}$, and emulsifier $700^{\#}$ were of amorphous state. Emamectin benzoate SME presented similar crystalline structure as sodium benzoate because most part in the nanoformulation composition was sodium benzoate. This crystal structure is beneficial to maintaining the formulation stability during storage compared with the amorphous form $[29,30]$.

3.5. Stability of SME. Changes of particle size and distribution of the SMEs during storage at room temperature are shown in Figure 6. The mean size of nanoparticles increased from $10.34 \mathrm{~nm}$ to $55.37 \mathrm{~nm}$ during 14 days of storage. This slight aggregation phenomenon is difficult to avoid, especially for nanoparticles [31]. However, the particle size still kept at about $64.27 \mathrm{~nm}$ after 30 days of storage, and PDI remained at around 0.35 . In addition, the redispersed microemulsion also presented colorless and transparent appearance. These results suggested the excellent physical stability of emamectin benzoate SME.

3.6. Biological Activity. The biological activities of emamectin benzoate SME and two kinds of WDGs against diamondback moths (Plutella xylostella L.) were compared in Table 4. The median lethal concentration (LC 50) of the emamectin benzoate SME was lower and the data showed that its toxicity was 1.3-fold that of the other two WDGs. As reported, the larvicidal effect enhanced with droplet size of pesticide decreasing and the above results are consistent with the literature [32]. Nanopesticides could be more potent to target organisms than bulk form and conventional formulations of pesticide because they have larger specific surface area which could increase the accumulation and uptake of the active ingredient by the pest $[32,33]$. 
TABLE 4: Bioassay results of emamectin benzoate SME and water dispersible granules.

\begin{tabular}{lcccc}
\hline Formulation & Toxicity regression equation & Correlation coefficient & LC 50 $(\mu \mathrm{g} / \mathrm{mL})$ & $95 \%$ confidence limit \\
\hline SME & $Y=6.8779+1.5677 x$ & 0.9387 & 0.0634 & $0.0012-0.2057$ \\
WDG-A & $Y=6.7968+1.6220 x$ & 0.9778 & 0.0830 & $0.0037-0.2188$ \\
WDG-B & $Y=7.0744+1.9262 x$ & 0.9755 & 0.0838 & $0.0028-0.2075$ \\
\hline
\end{tabular}

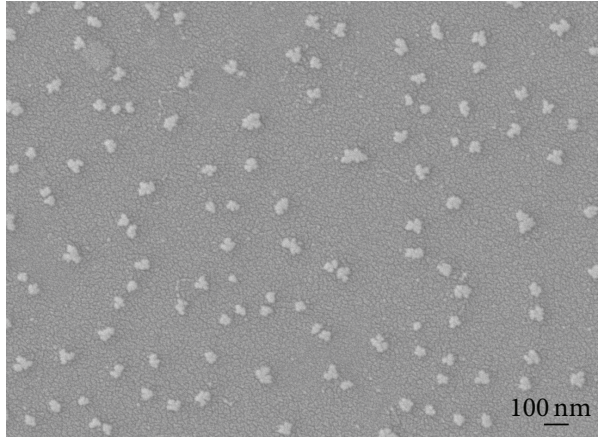

(a)

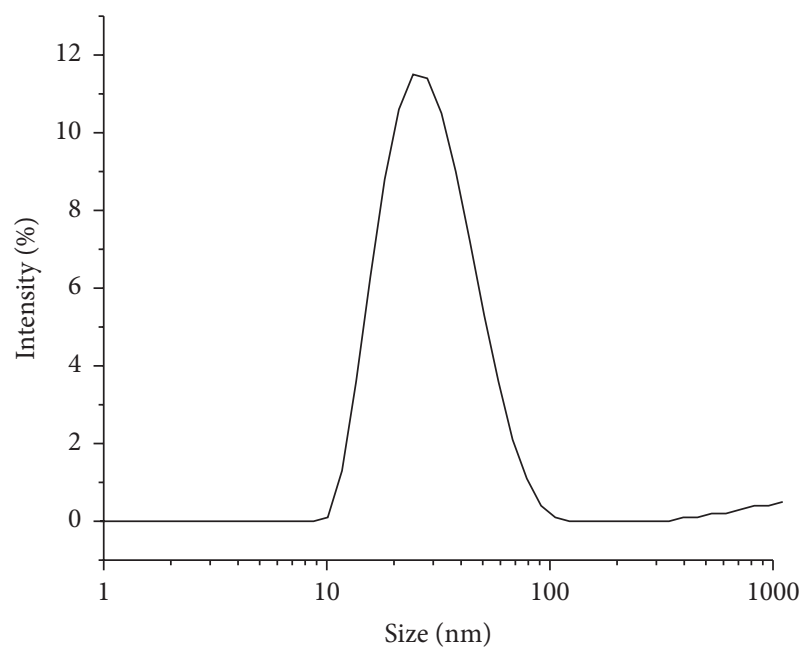

(b)

FIGURE 4: (a) SEM image of emamectin benzoate nanoparticles and (b) particle size distribution of emamectin benzoate SME measured by DLS.
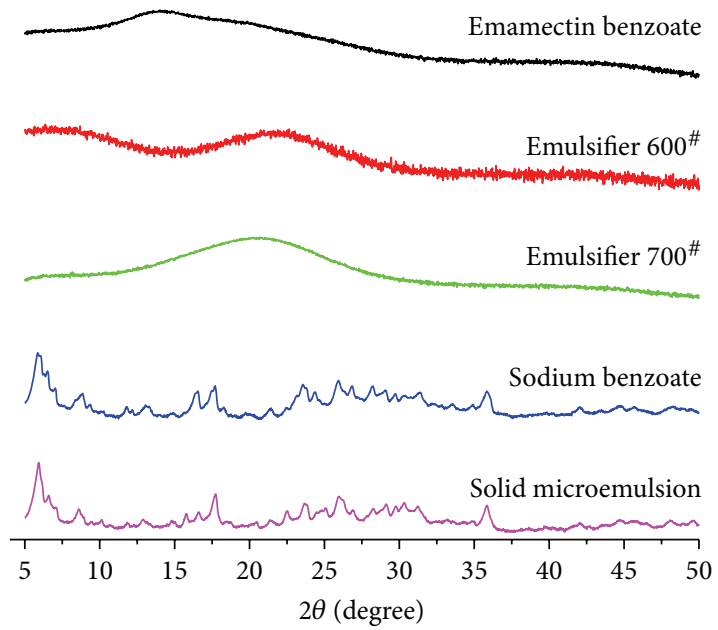

FIGURE 5: X-ray diffraction patterns of emamectin benzoate SME and related ingredients.

\section{Conclusion}

In summary, the solid microemulsions of emamectin benzoate were prepared by a self-emulsifying method. Emulsifier $600^{\#}$ and emulsifier $700^{\#}(3 / 2, \mathrm{w} / \mathrm{w})$ were optimized from eleven kinds of surfactants, and the content the same as pesticide was enough to exhibit excellent self-emulsifying feature. The solid microemulsion changed into aqueous microemulsion after redispersing by water and the mean

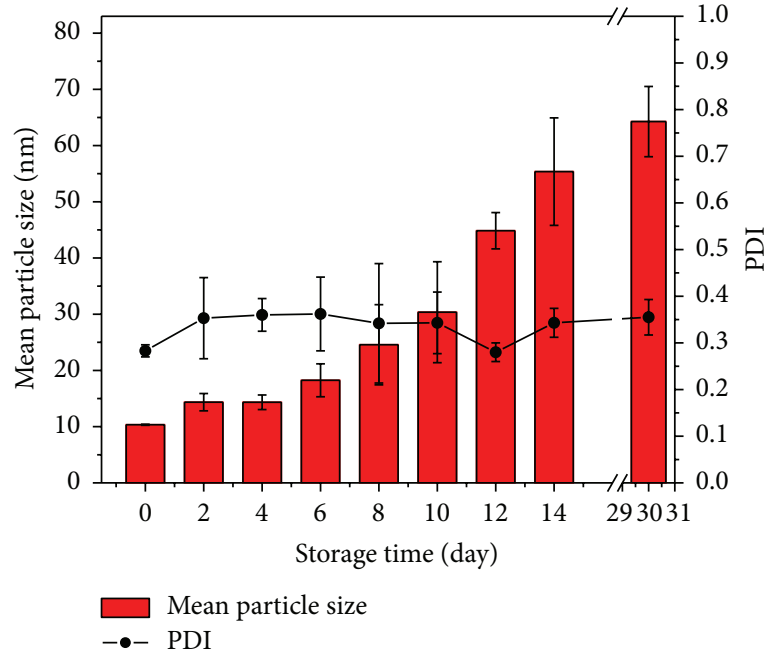

FIGURE 6: The changes of particle size and PDI of the emamectin benzoate SME during storage.

particle size was $10.34 \mathrm{~nm}$. In addition, the solid microemulsion had good stability and improved biological activity compared to conventional solid formulations. This research provides a simple and convenient method to produce solid nanoformulations and the solid microemulsion is perspective in plant protection for improving bioavailability and reducing environmental pollution. 


\section{Competing Interests}

The authors declare that they have no competing interests.

\section{Authors' Contributions}

Lei Feng and Bo Cui contributed equally to this work.

\section{Acknowledgments}

The research was supported by Major National Scientific Research Program of China (no. 2014CB932200) and Basic Scientific Research Foundation of National Non-Profit Scientific Institute of China (no. BSRF201406).

\section{References}

[1] B. S. Sekhon, "Nanotechnology in agri-food production: an overview," Nanotechnology, Science and Applications, vol. 7, no. 2, pp. 31-53, 2014.

[2] L. Chen, X. Yu, J. Chen, Q. Ye, and H. Fang, "Preliminary application of new formulation of pesticides in safety production of Jiaobai, Zizania caduciflora L," Acta Agriculturae Zhejiangensis, vol. 15, no. 3, pp. 177-180, 2003.

[3] N. Hua, "Advance and trend of pesticide formulation development," Agrochemicals, vol. 47, no. 3, pp. 79-81, 2008.

[4] J. Cao, M. Hu, and Z. Zhao, "Research on the formula of $5 \%$ acetamiprid EC," Journal of Anhui Agricultural Sciences, vol. 37, no. 12, pp. 5564-5564, 2009.

[5] N. Hua, "Progress, future and process technology of pesticides SC formulations," Modern Agrochemicals, vol. 6, no. 1, pp. 1-7, 2007.

[6] G. Zhang and L. Li, "The formulation technology of suspension concentrate products," World Pesticides, vol. 32, no. 4, pp. 10-17, 2010.

[7] P. Yang and P. Yang, "Research on formulation of 25\% trinexapac-ethly EC," Guangdong Chemical Industry, no. 2, pp. 18-19, 2013.

[8] J. Huang, "Developing tendency of surfactant used in pesticide in China," Fine Chemical Intermediates, vol. 33, no. 7, pp. 8-9, 2003.

[9] X. Zhang and J. Sun, "Surfactants in pesticides," Modern Chemical Industry, vol. 20, no. 2, pp. 13-18, 2000.

[10] L. Yang, "Problems and development trend of avermectins pesticide formulations," World Pesticides, vol. 31, pp. 5-7, 2009.

[11] A. Mihranyan and M. Strømme, "Solubility of fractal nanoparticles," Surface Science, vol. 601, no. 2, pp. 315-319, 2007.

[12] S. M. Dizaj, Z. Vazifehasl, S. Salatin, K. Adibkia, and Y. Javadzadeh, "Nanosizing of drugs: effect on dissolution rate," Research in Pharmaceutical Sciences, vol. 10, no. 2, pp. 95-108, 2014.

[13] S. B. Murdande, D. A. Shah, and R. H. Dave, "Impact of nanosizing on solubility and dissolution rate of poorly soluble pharmaceuticals," Journal of Pharmaceutical Sciences, vol. 104, no. 6, pp. 2094-2102, 2015.

[14] I. Ishaaya, R. Nauen, and A. R. Horowitz, Insecticides Design Using Advanced Technologies, Springer Ebooks, 2007.

[15] Y. Sasson, G. Levy-Ruso, O. Toledano et al., "Nanosuspensions: emerging novel agrochemical formulations," in Insecticides Design Using Advanced Technologies, pp. 1-39, Springer, Berlin, Germany, 2009.
[16] J. Zhu, Y. He, M. Gao et al., "Photodegradation of emamectin benzoate and its influence on efficacy against the rice stem borer, Chilo suppressalis," Crop Protection, vol. 30, no. 10, pp. 1356-1362, 2011.

[17] Q. Shang, Y. Shi, Y. Zhang, T. Zheng, and H. Shi, "Pesticideconjugated polyacrylate nanoparticles: novel opportunities for improving the photostability of emamectin benzoate," Polymers for Advanced Technologies, vol. 24, no. 2, pp. 137-143, 2013.

[18] X. Cheng, X. Liu, H. Wang et al., "Effect of emamectin benzoate on root-knot nematodes and tomato yield," PLOS ONE, vol. 10, no. 10, Article ID e0141235, 2015.

[19] M. Guo, W. Zhang, G. Ding et al., "Preparation and characterization of enzyme-responsive emamectin benzoate microcapsules based on a copolymer matrix of silica-epichlorohydrincarboxymethylcellulose," RSC Advances, vol. 5, no. 113, pp. 93170-93179, 2015.

[20] C. H. Zheng, "Development of a 1.0\% emamectin benzoate microemulsion," Anhui Chemical Industry, vol. 38, no. 3, pp. 4951, 2012.

[21] B. P. Sahu and M. K. Das, "Formulation, optimization, and in vitro/in vivo evaluation of furosemide nanosuspension for enhancement of its oral bioavailability," Journal of Nanoparticle Research, vol. 16, article 2360, 2014.

[22] M. P. Siqueira-Moura, F. L. Primo, E. M. Espreafico, and A. C. Tedesco, "Development, characterization, and photocytotoxicity assessment on human melanoma of chloroaluminum phthalocyanine nanocapsules," Materials Science and Engineering C, vol. 33, no. 3, pp. 1744-1752, 2013.

[23] Z. Zhu, M. Zhu, L. Hui, and J. Ma, "Influence of surfactant content on structure and properties of nano-zirconia powder prepared by the microemulsion method," Journal of the Chinese Ceramic Society, vol. 34, no. 7, pp. 788-791, 2006.

[24] F. Zhao, J. He, and H. Xia, "Study on formula design of pesticide microemulsion," Pesticide Science \& Administration, vol. 30, no. 11, pp. 26-30, 2009.

[25] T. T. Wang, Z. Y. Liu, R. S. Zhang, and H. Q. Qin, "Prepartion of the microemulsion of $3.3 \%$ imidacloprid and avermectin," Shandong Chemical Industry, vol. 37, no. 10, pp. 12-14, 2008.

[26] A. Abdalla and K. Mäder, "Preparation and characterization of a self-emulsifying pellet formulation," European Journal of Pharmaceutics \& Biopharmaceutics, vol. 66, no. 2, pp. 220-226, 2007.

[27] T. Yi, J. Wan, H. Xu, and X. Yang, "A new solid selfmicroemulsifying formulation prepared by spray-drying to improve the oral bioavailability of poorly water soluble drugs," European Journal of Pharmaceutics \& Biopharmaceutics, vol. 70, no. 2, pp. 439-444, 2008.

[28] W. Cho, M.-S. Kim, J.-S. Kim et al., "Optimized formulation of solid self-microemulsifying sirolimus delivery systems," International Journal of Nanomedicine, vol. 8, no. 1, pp. 1673-1682, 2013.

[29] J. Pardeike, D. M. Strohmeier, N. Schrödl et al., "Nanosuspensions as advanced printing ink for accurate dosing of poorly soluble drugs in personalized medicines," International Journal of Pharmaceutics, vol. 420, no. 1, pp. 93-100, 2011.

[30] C. Leuner and J. Dressman, "Improving drug solubility for oral delivery using solid dispersions," European Journal of Pharmaceutics \& Biopharmaceutics, vol. 50, no. 1, pp. 47-60, 2000.

[31] M. George and I. Ghosh, "Identifying the correlation between drug/stabilizer properties and critical quality attributes (CQAs) 
of nanosuspension formulation prepared by wet media milling technology," European Journal of Pharmaceutical Sciences, vol. 48, no. 1-2, pp. 142-152, 2013.

[32] C. H. Anjali, Y. Sharma, A. Mukherjee, and N. Chandrasekaran, "Neem oil (Azadirachta indica) nanoemulsion-a potent larvicidal agent against Culex quinquefasciatus," Pest Management Science, vol. 68, no. 2, pp. 158-163, 2012.

[33] C. H. Anjali, S. S. Sudheer Khan, K. Margulis-Goshen, S. Magdassi, A. Mukherjee, and N. Chandrasekaran, "Formulation of water-dispersible nanopermethrin for larvicidal applications," Ecotoxicology \& Environmental Safety, vol. 73, no. 8, pp. 19321936, 2010. 

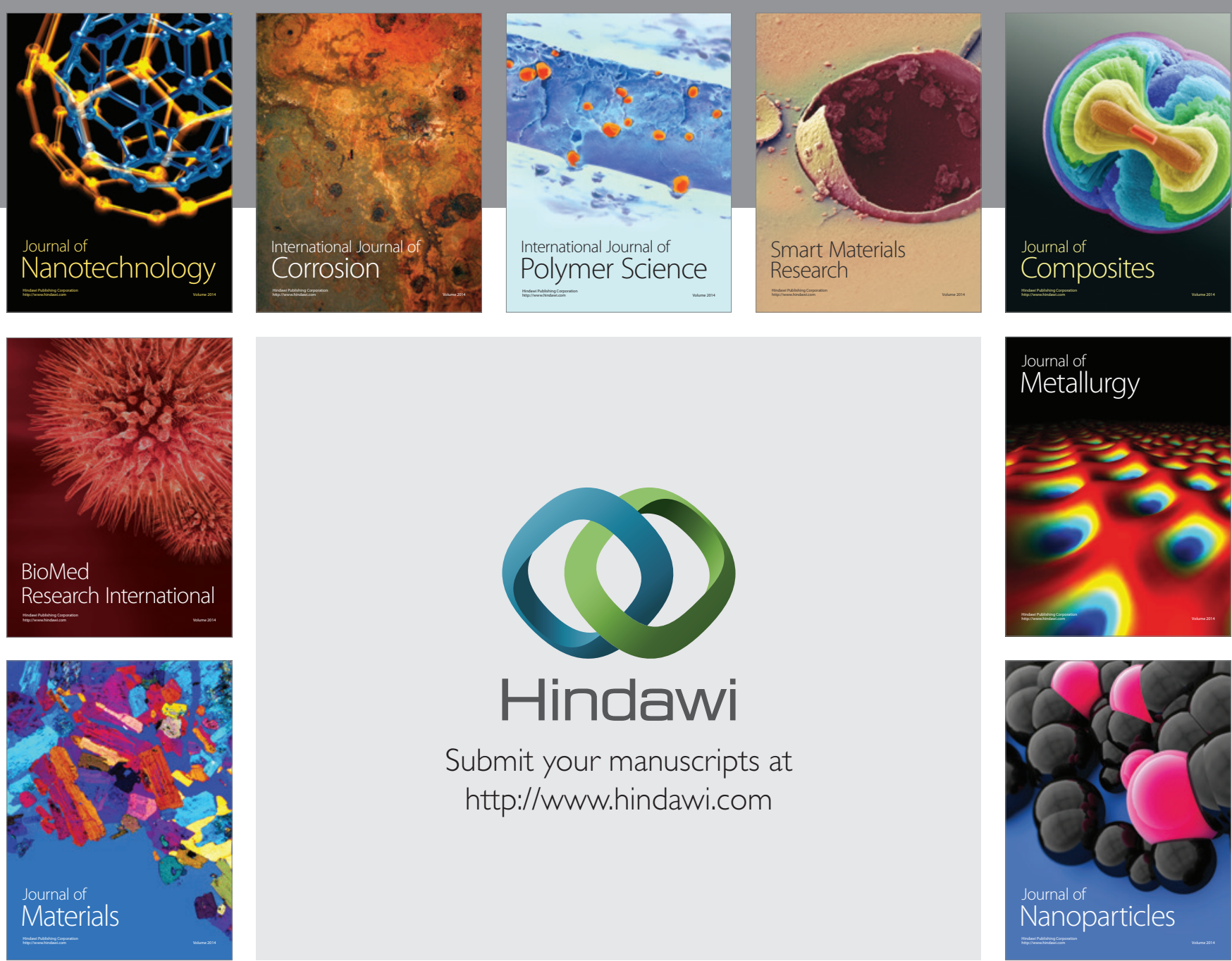

\section{Hindawi}

Submit your manuscripts at

http://www.hindawi.com

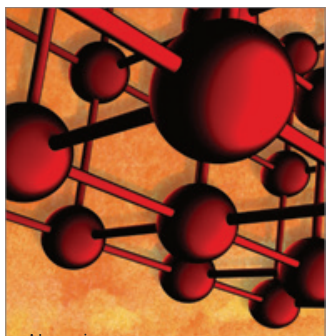

Materials Science and Engineering
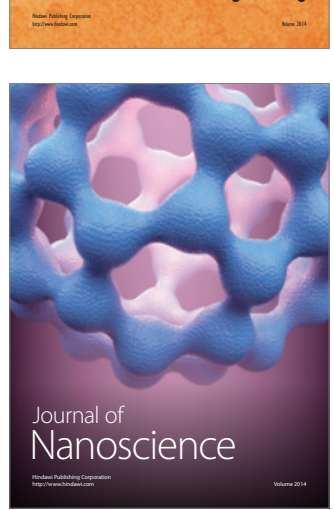
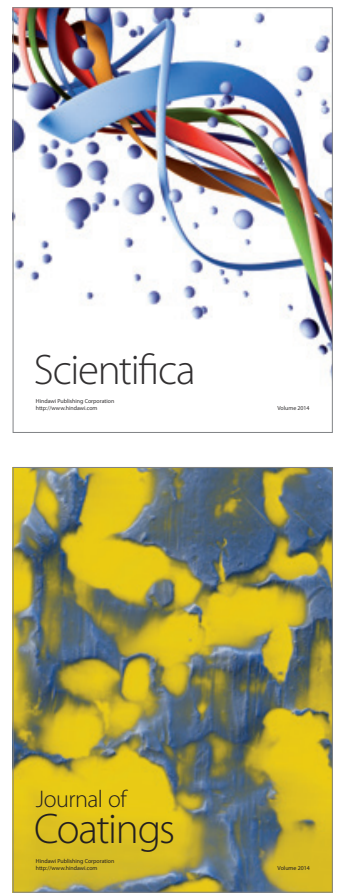
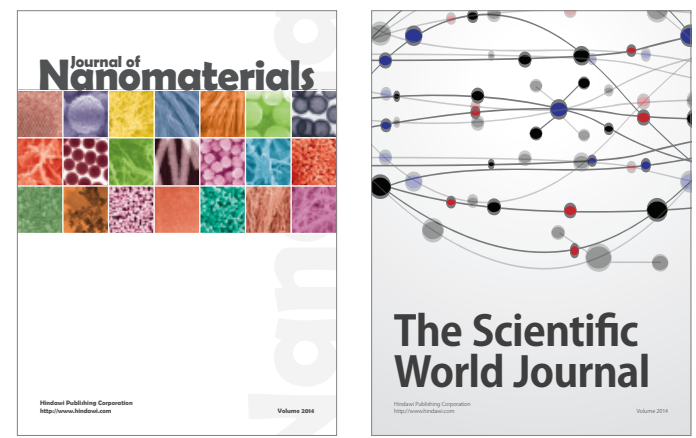

The Scientific World Journal
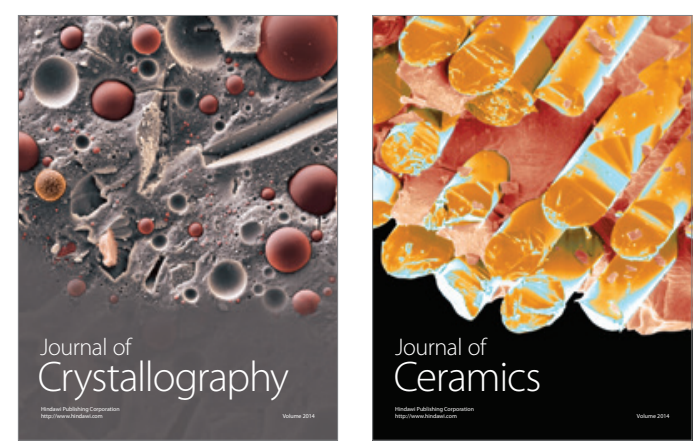
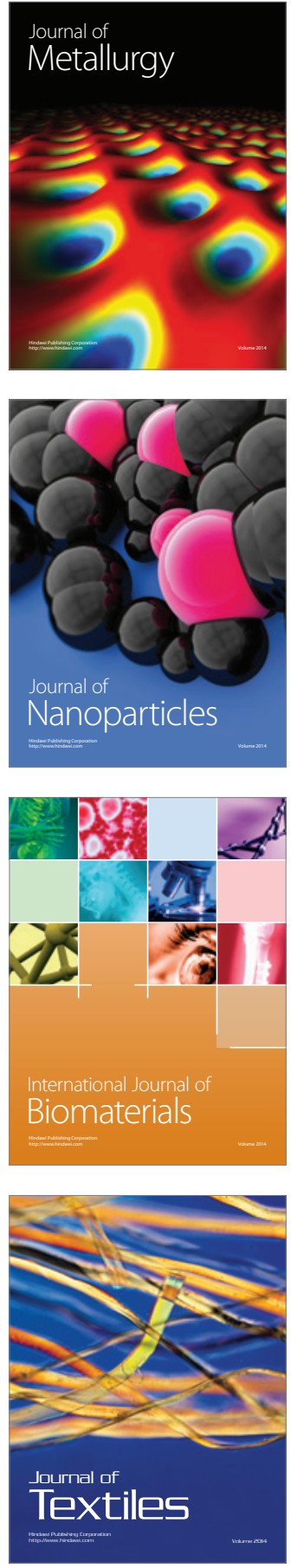